1 Title: The individual experience of ageing prisoners: systematic

2 review and meta-synthesis through a Good Lives Model framework

3

4

Running head: Systematic review on ageing prisoners.

7 Keywords: Prison, ageing prisoners, mental health, physical health, systematic review, meta-

8 synthesis.

\title{
Main points
}

- The experience of imprisonment from the perspective of ageing prisoners has received little attention in research.

- We adopted a prisoner-centred approach grounded in the Good Lives Model, to explore the experience of ageing prisoners, the elements of life in prison impacting on their wellbeing and the current service provision.

- We reviewed 25 international studies and developed through meta-synthesis three themes: The hardship of imprisonment, addressing health and social care needs and the route out of prison.

- We found that, despite initiatives to address their needs, the experience of incarceration for ageing prisoners is quite poor, which reflects the inconsistent support that they are usually offered.

Names of authors: Claudio Di Lorito, Birgit Völlm, Tom Dening

Name of institution where research was conducted: Division of Psychiatry and Applied Psychology, School of Medicine, University of Nottingham 
28 Corresponding author: Claudio Di Lorito, Room A10, Institute of Mental Health,

29 Innovation Park, University of Nottingham, Triumph Road, Nottingham, NG7 2TU, United

30 Kingdom. Email: claudio.dilorito@ nottingham.ac.uk. Phone: (+44) 07453717277

31

32 Name of Sponsor: CLAHRC East Midlands

33

34 Word count of body text: 4,494

35

36

37

38

39

40

41

42

43

44

45

46

47

48

49

50

51 
60

\section{5}

\section{Abstract}

Objective. The existing literature on ageing prisoners tends to focus on such aspects as diagnosis and physical ill-health. In contrast, the experience of imprisonment from the perspective of ageing prisoners has received less attention. Grounded in a Good Lives Model theoretical framework, we reviewed and meta-synthesised literature around their experience of life in prison, its impact on their wellbeing and how prison services are currently addressing their complex needs. We further identify potential areas of improvement.

Methods. 1. Systematic search on Assia, PsycInfo, MedLine, Embase, Web of Science, Google and Gov.uk. 2. Extraction and categorisation of data on NVivo. 3. Development of themes through thematic analysis and meta-synthesis. 4. Identification of potential areas of improvement.

Results. We selected 25 studies for our review, of which thirteen were from the USA, seven from the UK, two from Australia and one each from Ireland, Switzerland and Israel. We identified three themes: The hardship of imprisonment, addressing health and social care needs, and the route out of prison.

Conclusions. Ageing prisoners have unique and complex health and social care needs which, to varying degree across different countries, are mostly unmet. Promising initiatives to address their needs are emerging but, at present time, the overall experience of incarceration for the ageing prisoner is quite poor, given the inconsistent physical, emotional and social care support offered from prison intake to release and beyond. 
The number of ageing prisoners is growing in many countries. In the United Kingdom, the population of prisoners over 60 years old has increased eight times since 1990 (Senior et al., 2013). In the United States of America, Ireland and Australia, ageing prisoners have been identified as the fastest growing group (Joyce \& Maschi, 2016; Davoren et al, 2015; Cornish et al., 2016).

This increase has been determined by demographic factors such as the ageing of the population (Senior et al., 2013) and cultural factors, including less lenient treatment of ageing offenders (Yorston, 2015). This has been accompanied, in the UK context, by tougher sentencing policies, causing an increase in longer, life and indeterminate sentences (Moll, 2013), historical and "other offences" (+95\% between 1995 and 2005) (RECOOP, 2015).

Ageing prisoners have been identified as a special need population in relation to physical, mental and social health care (Atabay, 2009). Regarding their physical health, in addition to common ailments, whose incidence increases with age (e.g., arthritis, Parkinson's disease, dementia, diabetes) (Baidawi, 2015), they experience poorer health status compared to people

94 in the community, owing to their common histories of substance abuse and poor health management (Cooney \& Braggins, 2010). Deteriorating physical health impacts on the mobility and independence of ageing prisoners, who may require consistent social care.

In relation to mental health, a recent meta-analysis found that $38 \%$ of ageing prisoners suffer from 'any psychiatric disorder', with more than double the prevalence reported in community 100 studies (15\%) (Di Lorito, Völlm, \& Dening, 2017). The authors also found higher prevalence for depression, schizophrenia/psychoses and anxiety disorders. 
102 Several policies aim to address the complex health care needs of ageing prisoners, including the European Convention of Human Rights (ECHR) against inhuman treatment and the $8^{\text {th }}$ amendment to the US constitution (Williams et al., 2012; Wahidin, 2011). In the UK, ageing prisoners are granted equal care as people living in the community through the National

106 Institute for Health and Care Excellence (NICE) guidelines on mental wellbeing and

107 independence in ageing people (NICE, 2015) and the Care Act 2015, which gives local authorities legal responsibility for the social care and support needs of prisoners.

110 Consideration of individual needs is also a key principle of strength-based models for the

111 rehabilitation of offenders, which, in contrast with risk need responsivity (RNR) (Andrews \&

112 Bonta, 2010) focusing on risk reduction, resort to personal strengths to promote rehabilitation

113 (Robertson et al., 2011). Among the strength-based approaches, the Good Lives Model

114 (GLM) is gaining a central role in forensic policy and practice (Robertson et al., 2011),

115 following several international studies which yielded promising results in rehabilitation

116 outcomes (Barnao, Ward, \& Casey, 2016; Barnao, Ward, \& Robertson, 2016; Ward \& Willis,

117 2016; Chu \& Ward, 2015; Fortune et al., 2015; Lord, 2014).

119 The GLM is grounded in principles of human dignity and postulates that rehabilitation to

120 socially integrated lifestyles is attained when the prison system provides the

121 resources/support for the person to meet individual needs or "Primary goods" (Table 1)

122 (Laws \& Ward, 2011; Ward \& Maruna, 2007; Ward \& Stewart, 2003), by applying three 123 principles: individual needs. 

Analyses (PRISMA) (Moher et al., 2009). rehabilitation.

[Insert Table 1 near here] questions:

2. Human agency, which acknowledges the individual's ability to identify individual needs and act through socially integrated lifestyles to meet them.

3. Human rights, which gives back dignity to offenders, by recognising their own individuality and the need for prison services to implement tailored pathways of

These principles put the prisoner at the centre and therefore their subjective experience is crucial. Although a robust body of international literature exists around ageing prisoners, most studies rely on data collected through the input of stakeholders' groups other than prisoners (e.g. custodial staff), neglecting their subjectivity. Grounded on a GLM theoretical framework, this review provides a meta-synthesis of the literature around the experience of imprisonment through the perspective of the ageing prisoners and is guided by three research

(i). What is the subjective experience of imprisonment for the ageing prisoner?

(ii). What are the variables that most affect this experience?

(iii). How are prison services addressing the individual needs of ageing prisoners? 
Inclusion criteria:

152

- Study is on ageing prisoners. We systematically searched for terms related to the age domain, but we avoided a strict age inclusion criterion because:

(i). There is little consensus as to the age range of 'older' prisoners (Williams et al., 2012). Some contend that given that age 60 is the cut-off in community studies, 50 years old would apply to prisoners, who usually experience premature ageing, given their poor health habits and histories of substance abuse (Cooney \& Braggins, 2010). Others object that prisoners experience similar health problems as people in the community (Fazel et al., 2004). Given the absence of a resolution in the current debate and in order not to discard relevant sources a priori, we refrained from adopting a pre-determined age cut-off.

164

(ii). Prisoners feel that ageing is a highly subjective experience:

"There was an unusual reaction to the question "How old does a prisoner have to be before people treat him as an older prisoner?" Fourteen men suggested that this "depends on the man's physical and mental condition", Reed (1980).

- The primary interest of the study is the experience of imprisonment for the ageing prisoner including aspects that impact on this experience.

- Either sex.

- Any language and year of publication. 
176 Exclusion criteria:

- Studies on ex-prisoners or patients in forensic psychiatric settings, as they do not have current lived experience of imprisonment.

- Remand prisoners, as the experience of being temporarily detained in prison may greatly differ from that of sentenced prisoners.

- Studies which do not reflect the views of prisoners.

183

184 We ran our search in December 2015 and again in December 2016 to retrieve the most updated literature. We searched on 5 databases: Assia, PsycInfo, Embase, Medline and Web of Science and combined terms from three domains:

188 (i). The age domain, including: Age*, old*, aging, elderly, mature.

189 (ii). The prison domain, including: Prison*, imprison*, inmate*, incarcerat*, detain*, 190 detention*.

191 (iii). The health domain, including: Care, mental*, emotion*, physical*, health*, service, healthcare, psychotic, psychos*, psychiatr*, psycholog*, mental*, wellbeing.

194 The same strategy was used to identify further relevant literature through the first 100 hits on

195 Google and Gov.uk and by screening the reference pages of the studies we retrieved.

196

197 Quality screening of the studies

198 We undertook a quality screening of our sources using the Mixed Methods Appraisal Tool

199 (MMAT) - Version 2011 (Pluye et al., 2011), a validated screening tool for complex

200 systematic literature reviews that include qualitative, quantitative and mixed methods studies. 


\section{Data extraction and analysis}

202 Data were extracted onto NVivo 11 (QSR International Pty Ltd., 2012). We adopted a

203 deductive approach to Thematic Analysis (Braun \& Clarke, 2006) and extracted data which

204 were relevant to our research questions, but refrained from generating themes at the initial

205 stage. Only after extraction, based on the emerging topics, we developed tentative umbrella

206 themes and sub-themes. The task was undertaken by the main author, who proposed an initial

207 number of seven tentative themes to the research team.

209 Each team member studied the dataset, assessed the appropriateness of the tentative themes

210 individually and fed back to the group during successive team meetings. The process of meta-

211 synthesis of themes was iterative. A final number of three themes and titles reflecting their

212 content was agreed by all research team members.

\section{Results}

214 We retrieved 3,222 records; 3,199 were identified through the databases and 23 through

215 Google and Gov.uk. Following title or abstract screening, 3,120 were dismissed. The

216 remaining 102 were screened for duplicates and assessed for eligibility against the inclusion

217 criteria. Twenty-five studies were included in this review (Figure 1). [Insert Figure 1 near

218 here]

219

\section{Quality screening of the studies}

221 Twenty studies were screened for quality, all of which passed the preliminary screening;

222 therefore, none was excluded for poor quality. Five were not screened for quality as they

223 were not empirical (Baldwin \& Leete, 2012; Booth, 1989; Chaiklin, 1998; Hodel \& Sanchez,

224 2012; Moll, 2013). 
225 The scores ranged from 50 to 100 . Five articles totalled the maximum score (Allen et al., 2008; Doron, 2007; Fazel et al., 2004; Leigey, 2008; Reed, 1980). The qualitative studies (or

227 qualitative element of the studies) obtained mostly positive scoring in items 1.1 (data sources), 1.2 (data analysis), and 1.3 (discussion of how findings relate to the context). In relation to discussion around the researchers' influence in the interview process (item 1.4), negative scoring was attributed in all but three cases (Doron, 2007; Leigey, 2008; Reed, 1980).

For the quantitative studies (or quantitative element of the studies), mostly positive scoring was attributed for items 2.1 (sampling strategy) and 2.3 (tools for data collection). Information on response rates was instead poorly reported in most studies (item 2.4). The quality screening is reported fully in table 2. [Insert Table 2 near here]

\section{Study characteristics}

239 Sixteen studies were qualitative, nine were quantitative and three adopted mixed

240 methodologies. The publication year ranged from 1979 to 2016; most of the articles were

241 published from the mid 2000's onwards, following an increase in the prevalence of ageing

242 prisoners. Thirteen studies were from the USA, seven from the UK, two from Australia and one each from Ireland, Switzerland and Israel. In contrast to other countries, the US studies covered all years of publication, reflecting a longer tradition of prison literature in the USA.

246 Seven studies focused on the general experience of imprisonment; the remainder addressed 247 dementia $(n=4)$; death/suicide $(n=3)$; release from prison $(n=3)$; physical and/or mental health and related needs, including social care $(n=3)$; religion $(n=2)$; treatment for physical and mental health $(n=2)$; and forgiveness $(n=1)$. The studies from the USA and the UK covered 
the whole range of topics. Most studies concerning dementia were published since 2010, which reflects the increased prevalence and increasing research interest in the condition.

252

Most studies were peer-reviewed. We also included two unpublished theses (Leigey, 2008;

Reid, 1980), which we believe reduces potential publication bias. The study designs included both empirical and non-empirical methodologies. Study samples ranged from two to 263 prisoners. The age cut-off for inclusion in the studies ranged from 45 to 69 years old. Ten studies were conducted on just one prison and 12 studies looked at multiple sites (Table 3). [Insert Table 3 near here]

\section{Themes}

261 We derived three themes:

1. The hardship of imprisonment

2. Addressing health and social care needs

3. The route out of prison

The hardship of imprisonment

267 The first theme was the hardship of imprisonment experienced by ageing prisoners due to "Institutional thoughtlessness", the systematic neglect of age-related needs through a onesize-fits-all regime (Crawley, 2005). This was reflected in the access issues for inmates who have limited mobility, as reported by an ageing prisoner in the Irish prison system: 
275 In the UK context, many prisons dating back to the $19^{\text {th }}$ century do not fully comply with the

276 Disability Discrimination Act 2005, presenting narrow cell doors and inaccessible bathrooms

277 (Senior et al., 2013; Crawley, 2005). In addition, facilities are often located on upper floors

278 (Joyce \& Maschi, 2016). Limited accessibility, through a GLM perspective, leads to neglect

279 of the primary human need for healthy living and functioning (see Table 1), since the ageing

280 prisoners may be unable to use essential services for rehabilitation and wellbeing.

281

282 Another example of institutional thoughtlessness relates to dementia. Only few institutions

283 have actively worked to become dementia-friendly (i.e. promoting the inclusion of people

284 with dementia) (Fazel et al., 2002), mostly in the United States (Moll, 2013; Hodel \&

285 Sanchez, 2012) and in the UK, where HMP Norwich offers units for serious conditions,

286 including dementia, and HMP Exeter is developing a specialist service for dementia (Moll,

287 2013).

288

289 These units offer specialised group activities such as walking, reminiscing and training in

290 personal hygiene; modifications to the prison, including visual aids for easier navigation and quieter dining tables/zones (Hodel \& Sanchez, 2012); and specialist programmes, such as the “Gold Coats", an Alzheimer's Association sponsored buddy scheme in 11 California prisons, in which people with dementia are assisted by younger inmates in managing finances, food,

294 medications and cleaning (Baldwin \& Leete, 2010; Moll, 2013). Exceptions aside, however,

295 the overall picture appears less encouraging, as summarised by the CEO of Age Action, 296 Eamon Timmins: there is dementia awareness within the prison system" (Joyce \& Maschi, 2016). 
300 Institutional thoughtlessness was also reflected in activity programmes. Only $55 \%$ of prisons

301 in England and Wales offer age-friendly activities and in $67 \%$ these are not suitable for

302 inmates with mobility difficulties, who may become reluctant to venture out of their cell

303 (Crawley, 2005), remain active and engage in hobbies and recreational pursuits (see Table 1).

305 Social disengagement and loneliness is often exacerbated by loss of contact with family and 306 friends (Leigey, 2008) and age-related life events, such as the death of a spouse or friends

307 (Booth, 1989) and may lead to alienation from life (Moll, 2013; Crawley, 2005), or in GLM

308 terms, a loss of pleasure in the here and now (See Table 1). This was well summed up by an

309 ageing prisoner:

310

311 “Unfortunately, there's guys whether it be old age or just that killer thing of 'I don't care, I'll

312 just lie down in bed and I'll go asleep'...A lot of them here have given up" (Joyce \& Maschi,

313 2016)

315 In response to the hardship of imprisonment, ageing prisoners adopt various coping

316 mechanisms, such as religion and spirituality (Leigey, 2008). In contrast with younger

317 prisoners, who tend to hide their religious belief from their peers, ageing prisoners often pride

318 themselves over a rich spiritual life (Reed, 1980), which alleviates feelings of depression,

319 anxiety and fear (Bishop et al., 2014, Allen et al., 2013; Allen et al., 2008), thus promoting

320 "inner peace" (see Table 1). Attending religious ceremonies also represents an opportunity

321 for social life and connectedness (Reed, 1980).

323 Another important response to the hardship of imprisonment is the potential for reconciliation

324 and restitution. With the passage of time, prisoners may come to accept responsibility for 
325 their offence and their sentence. This may bring a change in attitude towards the victim(s) of

326 their crime and the judicial authority, as well as emerging personal forgiveness for their

wrongdoing (Bishop et al., 2014). Ageing prisoners also resort to reminiscing, the recalling of happy memories and/or challenging past events successfully dealt with, to find the strength to face the present (Crawley, 2005; Leigey'2008). Instead, counselling, psychotherapy and pastoral care were not reported as coping mechanisms. This may denote poor service provision in the prison system, which, as highlighted by Chaiklin (1998), is nonetheless crucial:

"One should distinguish between humanitarian care, therapeutic care, and custodial care. All are needed. There is also a need for crisis intervention...".

The second theme was care provision in the prison system. Our findings indicated that the complex physical, mental and social care health needs of ageing prisoners remain largely unmet, neglecting the primary good of healthy living and functioning (see Table 1).

This may occur because of the highly specialised care required, which may exert strain on the resources of the prison system (Booth, 1989). In the current economic climate, where optimisation of costs is often the priority, cuts in funding may result in poor service provision (Crawley, 2005).

347 In relation to physical and social health care needs, one barrier is represented by the emphasis on punishment over care, which makes custodial staff reluctant to respond to the ageing

349 prisoners" needs (Crawley, 2005) and by a "macho" culture, which considers attending to 
350 prisoners' needs as feminine (Moll, 2013). The negative impact of the prison culture is

351

352

353

354

355

356

357

358

359

360

361

362

363

364

365

366

367

368

369

370

371

372

373

374

reinforced by ageing prisoners being poorer self-advocates than the younger inmates (Doron, 2007). In an ageing prisoner's words:

"With the younger ones, they know they have to keep them healthy anyway because they'd be complaining and they'd be writing to the papers" (Joyce \& Maschi, 2016).

Physical health issues and social care needs may also pass unidentified, especially if untrained prison staff are unable to recognise symptoms or emerging social care needs (Baidawi, 2015). The overall discontentment around physical and social health led a prisoner to conclude that only by becoming persistent self-advocates, can ageing prisoners have their health and social care needs met (Loeb et al., 2007).

A similar neglect extends to mental health needs (Fazel et al., 2004), given the reticence of ageing prisoners to voice their needs, because of the stigma attached to psychiatric illness (Leigey, 2008) and the fear of being ridiculed by prison officers or fellow inmates (Baidawi, 2015). This concern is well supported by evidence, as Joyce and Maschi (2016) report that ageing prisoners are more frequently the victims of bullying compared to younger prisoners (38\% against $12 \%)$

A potential vehicle to address the complex physical, mental and social health care needs of ageing inmates is networking with charities/organisations specialised in old age, such as AgeUK or the Alzheimer's Society, which could offer professional advice (Baidawi, 2015). In England and Wales, however, only a third of prisons co-operate with external agencies (Senior et al., 2013). 
375 Given the neglect of basic needs, ageing prisoners report poor emotional wellbeing and 376 frequently engage in negative thinking. Some ageing prisoners may come to see death as

377 liberation from misery (Crawley \& Sparks, 2006; Aday, 2005). Handtke and Wangmo (2014)

378 report that $50 \%$ of ageing prisoners have suicidal thoughts, which are often undisclosed, as

379 being on suicide watch is stigmatising. In addition, suicide assessment is not carried out

380 regularly, making it more difficult to identify at-risk subjects (Barry et al., 2015).

381

382 Despite the overall poor service provision, our review also found some examples of good

383 practice, which are unevenly spread across countries and mostly depend on whether a

384 national policy on ageing prisoners exists. They nonetheless reflect a growing interest among

385 policy makers, the justice system and prison staff, in caring for the needs and wellbeing of

386 ageing prisoners.

387

388 In the UK, HMP Wymott offers weekly visits from healthcare assistants, who provide

389 support for bathing to prisoners with mobility issues; a programme of psychological

390 interventions; self-help books or referrals to chaplaincy in the occurrence of mental health

391 crises; and the delivery of age-friendly activities such as arts, yoga or cooking classes

392 (Crawley, 2005; Crawley \& Sparks, 2006).

393

394 In the Irish context, where prisons are not able to offer support services, social care has been

395 delegated to community-based organisations such as the Red Cross and the ageing prisoners

396 have welcomed the initiative:

397

398 "When they discovered that I had rheumatoid arthritis, they asked the Red Cross to arrange

399 to bring my meals...They're very well organised" (Joyce \& Maschi, 2016) 
401 As per the GLM principles, to sustain the process of rehabilitation, prisoners must fulfill their

402 need for connection with the wider community (see Table 1), once they are released from

403 prison. However, the evidence suggests that around 50\% of ageing prisoners experience

404 homelessness and/or destitution upon release (Senior et al., 2013; Joyce \& Maschi, 2013).

405 This is likely to result from limited information around resettlement arrangements (Senior et 406 al., 2013) and poor liaison strategies between prisons, probation services and offenders'

407 managers.

408

409 Pre-release courses are offered in a minority of prisons, but these rarely cater for individual

410 needs (Senior et al., 2013). Therefore, the soon-to-be-released prisoners tend to rely on the

411 information of other inmates, which is often inaccurate and generates high levels of anxiety

412 (Senior et al., 2013). Most ageing prisoners fear being relocated with younger ex-offenders

413 (Crawley \& Sparks, 2006) and becoming the victims of physical and verbal intimidation

414 (Forsyth et al., 2015) and have concerns around economic uncertainty upon resettlement,

415 which may impact on their health (Crawley \& Sparks, 2006; Loeb et al., 2007).

416

417 Given these uncertainties, prison may be seen as a protective environment (Doron, 2007, 418 Aday \& Webster, 1979). For example, healthcare provision, though far from being ideal, 419 grants a level of security that could be lacking in the community (Handtke \& Wangmo, 420 2014). This applies especially to the US health care system and to prisoners living in geriatric 421 hospital wings which provide highly specialised treatments (Doron, 2007). As one ageing 422 prisoner stated: 
“Not long ago I sat down and analysed my situation. Heck, I couldn't work outside...I'm

better off here than I would be anywhere...I have friends in here...My medications and

everything are there when I need them" (Aday, 1994)

\section{Discussion}

429 This systematic review adds to the current field of knowledge around ageing prisoners for several reasons:

1. It is the first review grounded upon the evidence-based and increasingly applied

Our review confirmed that ageing prisoners have unique health and social care needs, which at present are only partially met. This has implications for research and practice. Given their direct daily contact with the inmates, prison staff are crucial in identifying and referring prisoners with emerging health issues to health care professionals. Therefore, basic awareness training for prison staff and a change of culture to view prisoners as patients, are required

448 (Crawley, 2005). In the United States, the Community Aging Health Project has extended 
449 geriatric training to all professionals working in the justice system (Ahalt \& Williams, 2015).

450 Similar initiatives do not seem to exist in other countries.

451

452 Given that the remit of custodial staff does not extend to health and social care, effective

453 work of a multi-disciplinary team, which includes health and social care professionals, is

454 essential. These professionals should be capable to work at three levels:

455 (i). Prevention, by developing and implementing programmes that promote physical and 456 mental health.

457 (ii). Identification of emerging needs, through team work with custodial staff;

458 (iii). Intervention, which requires expertise around age-associated conditions and the

459 difficulties that these entail.

460

461 Improvement in health and social care also depends on the regular administration of health screenings, which, at present, are systematically carried out at intake but not afterwards.

463 These would further facilitate the identification of social care needs and the allocation of 464 support.

465

466 Adequate policy development and implementation is also required. In the UK, the Care Act 4672015 may represent a turning point in the social care of ageing prisoners, who constitute $42 \%$ 468 of all prisoner referrals for assessment of social care and support (Anderson, 2015). A report 469 of the ADASS (Association of Directors of Adult Social Services) following the introduction 470 of the new legislation, however, has denounced that so far a very limited number of referrals 471 for social care has been made to local councils and concluded that integration between health 472 and social care still needs to be achieved in the prison system (Anderson, 2015). 
474 In this sense, local authorities should promote cooperation between support providers (e.g.

475 NHS), prison staff, health commissioners and the National Offender Management Service

476 (NOMS) to ensure good practice. Interdisciplinary work between different agencies is also

477 fundamental to support the $95 \%$ of ageing prisoners who are eventually reintegrated in the

478 community, many of whom need long-term social care (Williams et al., 2012).

479

480 In relation to the health and social care needs of terminally-ill ageing prisoners, different

481 countries have implemented different strategies, including pre-term compassionate release,

482 specialised units for ageing prisoners, hospice and palliative care and assisted suicide. Pre-

483 term compassionate release (i.e. reintegration of a terminally-ill prisoner in the community

484 when it offers more suitable treatment than the prison) is common in France (Steiner, 2003),

485 but it can be controversial with sexual offenders. Thus, in the US and the UK, requirements

486 are often strict and few prisoners benefit from compassionate release (Williams et al., 2012).

487

488 A compromise between security and treatment is offered by specialised geriatric prison units,

489 which are the subject of a heated debate. Some argue that they require large financial

490 investments, promote age segregation, lack stimulation, and discourage family visits, if

491 located further than general prisons (Howse, 2003). They also contend that ageing inmates

492 exert a calming effect on the younger prisoners in a mixed environment (Howse, 2003).

493 Others object that these units offer humane and specialist care in a safer environment (Fazel

494 et al., 2004).

495

496 Undoubtedly, dedicated units for the ageing patients could provide opportunities for

497 improving end of life care. In Switzerland, assisted suicide is legal practice for terminally-ill

498 prisoners (Handtke \& Wangmo, 2014). The prison hospice care movement in the United 
499 States has led to the wide implementation of in-prison palliative and hospice care, which

500 ensures emotional and physical support for dying prisoners, while preserving their human

501 rights. In other countries, such as the United Kingdom, this is still less common (Docherty,

502 2009).

503

504

\section{Limitations}

505

506

This review has some limitations. Most of the studies were carried out in the UK and the

507 USA; our findings may therefore be less generalisable to other countries. Nonetheless, the

508 phenomenon of an ageing prison population is also seen in countries with different traditions

509 of legal justice, such as Japan (Williams et al., 2012). Therefore, we feel that our findings are

510 relevant to inform good practice in a variety of contexts.

511

512 Further limitations derive from the quality of the studies included. Five studies used non-

513 empirical methodologies, which reduces confidence in their findings. In addition, we could

514 only retrieve one study reporting on ageing female prisoners (Joyce \& Maschi, 2016), thus

515 potentially incurring a gender selection bias. Selection bias may have also been caused by the

516 fact that almost a third of the studies $(\mathrm{n}=10)$ were single-site.

517

518 Finally, four studies were carried out more than 20 years ago, thus providing data that do not

519 necessarily reflect the current situation. Nonetheless, we observe that their results are

520 consistent with those reported in more recent literature. This suggests that their findings are

521 still valid, and/or that there have been no substantial advances over the years in addressing

522 ageing prisoners' needs. 
524 Our review found that ageing prisoners have unique and complex health and social care needs

525 which are mostly unmet. There is an interest in this population, which is reflected in

526 initiatives aimed at their wellbeing. However, at present time, the overall experience of

527 incarceration for the ageing prisoner is quite poor, given the inconsistent physical, emotional

528 and social care support offered from prison intake to release and beyond.

529

530 Disclaimer: The research was funded by the NIHR Collaboration for Leadership in Applied

531 Health Research and Care East Midlands (CLAHRC EM). The views expressed are those of

532 the authors and not necessarily those of the NHS, the NIHR or the Department of health.

533

534

535

536

537

538

539

540

541

542

543

544

545 
548 Aday, R. H. (1994). Aging in prison: A case-study on new elderly offenders. International Journal of Offender Therapy and Comparative Criminology, 38(1), 79-91.

550

Aday, R. H. (2005). Aging prisoners' concerns toward dying in prison. Journal of Death and 552 Dying, 52(3), pp. 199-216. doi:http://dx.doi.org/10.2190/CHTD-YL7T-R1RR-LHMN

Aday, R., \& Webster, E. (1979). Aging in Prison: The Development of a Preliminary Model. Offender Rehabilitation 3(3), 271-282.

556

Ahalt, C., \& Williams, B. (2015). How can criminal justice systems from police to probation address the medical and social care needs of elderly prisoners? Available at: https://www.penalreform.org/blog/declining-health-advancing-years-prison-callpolicy-oriented/ [Accessed 25 Oct. 2016]

561

Allen, R. S., Phillips, L. L., Roff, L. L, Cavanaugh, R., \& Day, L. (2008). (2013). Does religiousness and spirituality moderate the relations between physical and mental health among aging prisoners? International Journal of Geriatric Psychiatry, 
Anderson, I. (2015). A report on the findings of the ADASS (Association of Directors of Adult Social Services) survey of social care activity in prisons and approved premises Quarter 1 2015/16. Available at: https://www.adass.org.uk/media/4231/an-analysis-of$\underline{\text { social-care-activity-in-prisons-and-approved-premises.pdf [Accessed } 10 \text { May 2017]. }}$

Andrews, D. A., \& Bonta, J. (2010). The psychology of criminal conduct (5th Edition). New Providence, NJ: LexisNexis.

Atabay, T. (2009). Handbook on prisoners with special needs. United Nations Publications. Vienna, Austria: United Nations Office on Drugs and Crime.

Baidawi, S. (2015). Older prisoners: Psychological distress and associations with mental health history, cognitive functioning, socio-demographic, and criminal justice factors. International Psychogeriatrics, 28(3), 385-395.

$$
\text { doi:http://dx.doi.org/10.1017/S1041610215001878 }
$$

Baldwin, J., \& Leete, J. (2012). Behind bars: the challenges of an ageing population. Australian Journal of Dementia care, 2(1), 16-19.

Barnao, M., Ward, T., \& Casey, S. (2016). Taking the good life to the institution: Forensic service users' perceptions of the Good Lives Model. International Journal of Offender Therapy and Comparative Criminology, 60(7), 766-786.

Barnao, M., Ward, T., \& Robertson, P. (2016) The Good Lives Model: A New Paradigm for Forensic Mental Health. Psychiatry, Psychology and Law, 23(2), 288-301. 
596 Barry, L. C., Wakefield, D. B., Trestman, R. L., \& Conwell, Y. (2015). Active and passive 597 suicidal ideation in older prisoners. The Journal of Crisis Intervention and Suicide 598 Prevention, 37(2), 88-94. doi:http://dx.doi.org/10.1027/0227-5910/a000350

599

600 Bishop, A. J., Randall, G., \& Merten, M. J. (2014). Consideration of forgiveness to enhance 601 the health status of older male prisoners confronting spiritual, social, or emotional 602 vulnerability. Journal of Applied Gerontology, 33(8), 998-1017.

603 doi:http://dx.doi.org/10.1177/0733464812456632

604

605

606

Booth, D. E. (1989). Health Status of the Incarcerated Elderly. Journal of Offender

607

608

Braun, V., \& Clarke, V. (2006). Using thematic analysis in psychology. Qualitative

609 Research in Psychology, 3(2), 77-101.

610

611 Chu, C. M., \& Ward, T. (2015). The good lives model of offender rehabilitation: Working

612 positively with sex offenders. In Ronel, N. \& Segev, D. (eds.) Positive Criminology.

613 Abingdon, United Kingdom: Routledge, pp. 140-161

614

615 Chaiklin, H. (1998). The elderly disturbed prisoner. Clinical Gerontologist: The Journal of 616 Aging and Mental Health, 20(1), 47-62.

617

618 Convention for the Protection of Human Rights and Fundamental Freedoms (European

619 Convention on Human Rights, as amended) (ECHR) art. 3.

620 
621 Cooney, F., \& Braggins, J. (2010). Doing time. Good practice with older people in prison622 The views of prison staff. London: Prison Reform Trust.

623

624 Cornish, N., Kimmett, E., Hewson, A., \& War S. (2016). Social care or systematic neglect? 625 Older people on release from prison. London: Prison Reform Trust.

626

627 Crawley, E. (2005). Institutional thoughtlessness in prisons and its impacts on the day-to-day 628 prison lives of elderly men. Journal of Contemporary Criminal Justice, 21(4), 350$629 \quad$ 363. doi: $10.1177 / 1043986205282018$

630

631 Crawley, E., \& Sparks, R. (2006). Is there life after imprisonment? How elderly men talk 632 about imprisonment and release. Criminology and Criminal Justice, 6(1), 63-82.

634

Davoren, M., Fitzpatrick, M., Caddow, F., Caddow, M., O’Neill, C., O’Neill, H., \& doi:10.1177/1748895806060667

637 Kennedy, H. (2014). Older men and older women remand prisoners: mental illness,

638 physical illness, offending patterns and needs. International Psychogeriatrics, 27(5),

639

Department of Health (2001). National Framework for Older People. London: Department of 641 Health.

642

643 Di Lorito, C., Völlm, B., \& Dening, T. (2017). Psychiatric disorders among older prisoners: 644 A systematic review and comparison study against older people in the community. Aging 645 and Mental Health. 2017 Feb 7:1-10. doi: 10.1080/13607863.2017.1286453. [Epub ahead 
of print].

647

648 Docherty, J. L. (2009). The Healthcare Challenges of Older People in Prisons - a briefing 649 paper. Prison Health Research Network. Available at:

650 http://www.ohrn.nhs.uk/resource/Research/OlderPrisonersReview.pdf [Accessed 18 Nov.

$6512016]$.

652

653 Doron, I. (2007). Heaven or hell? Aging behind bars in Israel. International Journal of Aging, 654 9(2), 145-159. doi:http://dx.doi.org/10.2190/HA.9.2.e

655

656 Fazel, S. (2014). Older people and the criminal justice system. In J. Gunn and P. J. Taylor 657 eds., Forensic Psychiatry: Clinical, legal and ethical issues. London: Taylor and Francis, $658 \quad$ pp. $523-528$.

659

660 Fazel, S., Hope, T., O'Donnell, I., \& Jacoby, R. (2004). Unmet treatment needs of older 661 prisoners: a primary care survey. Age \& Ageing, 33(4), 396-398.

662

663 Fazel, S., McMillian, J., \& O'Donnell, I. (2002). Dementia in prison: Ethical and legal 664 implications. Journal of medical Ethics, 28(3), 156-159.

665

666 Forsyth, K., Senior, J., Stevenson, C., O'Hara, K., Hayes, A., Challis, D., \& Shaw, J. (2015).

667 'They just throw you out': Release planning for older prisoners. Ageing \& Society, 35(9), 668 2011-2025. doi:http://dx.doi.org/10.1017/S0144686X14000774

669

670 
671 Fortune, C. A., Ward, T., \& Mann, R. (2015). Good lives \& the rehabilitation of sex

672 offenders: A positive treatment approach. In: Linley, A. \& Joseph S. (eds.) Positive

673 psychology in practice (2nd ed.). Hoboken, NJ: John Wiley \& Sons.

674

675 Handtke, V., \& Wangmo, T. (2014). Ageing prisoners' views on death and dying:

676 contemplating end-of-life in prison. Journal of Bioethical Inquiry, 11(3), 373-386.

677 doi:http://dx.doi.org/10.1007/s11673-014-9548-x

678

679 Hodel, B., \& Sanchez, H. G. (2012). The Special Needs Program for Inmate-Patients with 680 Dementia (SNPID): a psychosocial program provided in the prison system. Dementia, 681 12(5), 654-660. doi:http://dx.doi.org/10.1177/1471301211432952

682

683 Howse, K. (2003). Growing old in prison: a scoping study on older prisoners. London: Prison 684 Reform Trust. Available at: http://www.prisonreformtrust.org.uk/uploads/documents/Growing.Old.Book___small.pdf

686 [Accessed on 5 Dec. 2016]

687

688

689

Joyce, J., \& Maschi, T. (2016). “In here, time stands still”. The rights, needs and

690

691

Laws, D. R., \& Ward, T. (2011). Desistance from sex offending: Alternatives to throwing 692 away the keys. New York, NY: The Guilford Press.

693

694 Leigey, M. E. (2008). Life while serving life: Examining the correctional experiences of 695 older inmates serving a life without parole sentence. Dissertation Abstracts International 
697

698 Loeb, S. J., Steffensmeier, D., \& Myco, P. M. (2007). In their own words: older male

699 prisoners' health beliefs and concerns for the future. Geriatric Nursing, 28(5), 319-

700 329. doi:http://dx.doi.org/10.1016/j.gerinurse.2007.02.001

701

702 Lord. A. (2014). Integrating risk, the Good Lives Model and recovery for mentally

703 disordered sexual offenders. Journal of Sexual Aggression, 22(1), 107-122.

704

705 Moher, D., Liberati, A., Tetzlaff, J., \& Altman, D. G., The PRISMA Group (2009).

706 Preferred Reporting Items for Systematic Reviews and Meta- Analyses: The PRISMA

707 Statement. PLoS Med, 6(7), e1000097. doi:10.1371/journal.pmed1000097

708

709 Moll, A. (2013). Losing track of time: dementia and the ageing prison population. Mental

$710 \quad$ Health Foundation, London. Available at:

711 http://www.mentalhealth.org.uk/content/assets/PDF/publications/losing-track-of-time-

712 2013.pdf?view=Standard [Accessed 10 Oct. 2015]

713

714 National Institute for Health and Care Excellence (2015). Mental Wellbeing and

715 independence in older people. NICE guideline (NG32). London: National Institute for

$716 \quad$ Health and Care Excellence.

717

718 NVivo qualitative data analysis Software (2012). Melbourne, Australia: QSR International 719 Pty Ltd.

720 
Pluye, P., Robert, E., Cargo, M., Bartlett, G., O’Cathain, A., Griffiths, F., Boardman, F., Gagnon, M.P., \& Rousseau, M.C. (2011). Proposal: A mixed methods appraisal tool for systematic mixed studies reviews. Available at: http://mixedmethodsappraisaltoolpublic.pbworks.com [Accessed on 12 May 2017]

Reed, M. B. (1980). Aging in a total institution: The case of older prisoners (Doctoral Dissertation). Available at: https://www.ncjrs.gov/pdffiles1/Digitization/65232NCJRS.pdf [Accessed 10 Dec 2016]

Resettlement and Care for Older ex-Offenders and Prisoners (RECOOP) (2015). Available at: http://www.recoop.org.uk/pages/resources/ [Accessed on 25 Oct. 2016]

Robertson P., Barnao, M., \& Ward, T. (2011). Rehabilitation frameworks in forensic mental health. Aggression and Violent Behavior, 16(6), 472-484.

Senior, J., Forsyth, K., Walsh, E., O'Hara, K., Stevenson, C., Hayes, A. C., Short, V., Webb, R., Challis, D., Fazel, S., Burns A. and Shaw, J. (2013). Health and social care services for older male adults in prison: the identification of current service provision and piloting of an assessment and care planning model. Health Services and Delivery Research, 1(5). doi:10.3310/hsdr01050

Steiner, E. (2003). Early release for seriously ill and elderly prisoners: Should French practice be followed? Probation Journal, 50(3), 267-276. 
Wahidin, A. (2011). Ageing behind bars, with particular reference to older women prisoners in prison. Irish Probation Service, 8, 109-123.

748

Ward, T., Mann, R. E., \& Gannon, T. A. (2007). The Good Lives Model of offender rehabilitation: Clinical implications. Aggression and Violent Behavior, 12(1), 87-107.

Ward, T., \& Maruna, S. (2007). Rehabilitation: Beyond the risk paradigm. London, UK: Routledge.

754

Ward, T., \& Stewart, C. A. (2003). The treatment of sex offenders: Risk management and good lives. Professional Psychology, Research and Practice, 34(4), 353-360.

Ward, T. \& Willis, G. (2016). Dynamic Risk Factors and Offender Rehabilitation: A Comparison of The Good Lives Model and The Risk-Need Responsivity Model. In: Laws, D. R. \& O'Donohue, W. (eds.). Treatment of sex offenders: Strengths and weaknesses in

Williams, B. A., Stern, M. F., Mellow, J., Safer, M., \& Greifinger, R. B. (2012). Aging in assessment and intervention. New York, NY: Springer, pp 175-190. correctional custody: Setting a policy agenda for older prisoner health care. American journal of Public health, 102(8), 1475-1481.

767 Yorston, G. A. (2015). Managing aggression and violence in older people. In G. Dickens, P. 768 Sugarman and M. Picchioni eds., Handbook of secure care (179-192). London: The Royal 769 College of Psychiatrists. 


\begin{tabular}{|l|l|}
\hline Primary good & Notes \\
\hline 1. Life & Includes healthy living and functioning \\
\hline 2. Knowledge & How well informed about things that are important to them \\
\hline 3. Excellence in play & Hobbies and recreational pursuits \\
\hline 4. Excellence in work & Includes mastery experiences \\
\hline 5. Excellence in agency & Autonomy, power and self-directedness \\
\hline 6. Inner peace & Freedom from emotional turmoil and stress \\
\hline 7. Relatedness & Including intimate, romantic, and familial relationships \\
\hline 8. Community & Connection to wider social groups \\
\hline 9. Spirituality & In the broad sense of finding meaning and purpose in life \\
\hline 10. Pleasure & Feeling good in the here and now \\
\hline 11. Creativity & Expressing oneself through alternative forms \\
\hline
\end{tabular}


Figure 1. Selection of papers

Records identified through databases (Assia, PsycInfo, MedLine, Embase and Web of Science) $(n=2,615)$

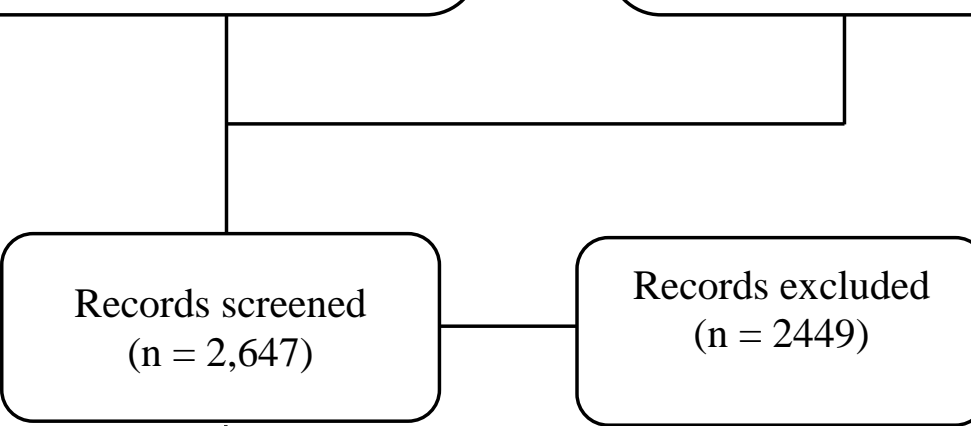

Additional records identified through

Google and Gov.uk $(n=32)$

Articles excluded $(\mathrm{n}=173)$

- On forensic psychiatry $(n=15)$

Full-text articles assessed for eligibility $(n=198)$

Studies included in

$$
(\mathrm{n}=25)
$$

- On ex-prisoners $(\mathrm{n}=26)$

- On prisoners in temporary incarceration $(n=42)$

- On offenders $(\mathrm{n}=46)$

- Did not reflect the views of prisoners $(n=44)$ 
Table 2. Study quality screening through the MMAT (Pluye et al., 2011)

\begin{tabular}{|c|c|c|c|c|c|c|c|c|c|c|c|c|c|c|}
\hline \multirow[t]{2}{*}{ Article } & \multicolumn{2}{|c|}{ Screening* } & \multicolumn{4}{|c|}{ Qualitative studies } & \multicolumn{4}{|c|}{ Quantitative studies } & \multicolumn{3}{|c|}{ 3. Mixed methods** } & \multirow[t]{2}{*}{ Score ${ }^{* * *}$} \\
\hline & $\mathbf{A}$ & B & 1.1 & 1.2 & 1.3 & 1.4 & 2.1 & 2.2 & 2.3 & 2.4 & 3.1 & 3.2 & 3.2 & \\
\hline Aday, 1994 & $\sqrt{ }$ & $\checkmark$ & $\checkmark$ & $\checkmark$ & $\checkmark$ & $x$ & & & & & & & & 75 \\
\hline Aday, 2005 & $\sqrt{ }$ & $\checkmark$ & $\checkmark$ & $\checkmark$ & $x$ & $x$ & $\checkmark$ & $\checkmark$ & $\checkmark$ & $\checkmark$ & $\sqrt{ }$ & $\sqrt{ }$ & $x$ & 72 \\
\hline Aday \& Webster, 1979 & $\sqrt{ }$ & $\checkmark$ & $\checkmark$ & $\checkmark$ & $\checkmark$ & $x$ & $\checkmark$ & $\checkmark$ & $x$ & $x$ & $\sqrt{ }$ & $\checkmark$ & $x$ & 63 \\
\hline Allen et al., 2013 & $\sqrt{ }$ & $\checkmark$ & & & & & $\checkmark$ & $x$ & $\checkmark$ & $x$ & & & & 50 \\
\hline Allen et al., 2008 & $\sqrt{ }$ & $\checkmark$ & & & & & $\checkmark$ & $\checkmark$ & $\checkmark$ & $\sqrt{ }$ & & & & 100 \\
\hline Baidawi, 2015 & $\checkmark$ & $\checkmark$ & & & & & $\checkmark$ & $\checkmark$ & $\checkmark$ & $x$ & & & & 75 \\
\hline Baldwin \& Leete, 2012 & \multicolumn{14}{|c|}{ Non-empirical } \\
\hline Barry et al., 2015 & $\sqrt{ }$ & $\checkmark$ & & & & & $\checkmark$ & $x$ & $\checkmark$ & $x$ & & & & 50 \\
\hline Bishop et al., 2014 & $\checkmark$ & $\checkmark$ & & & & & $\checkmark$ & $x$ & $\checkmark$ & $x$ & & & & 50 \\
\hline Booth, 1989 & \multicolumn{14}{|c|}{ Non-empirical } \\
\hline Chaiklin, 1998 & \multicolumn{14}{|c|}{ Non-empirical } \\
\hline Crawley, 2005 & $\sqrt{ }$ & $\checkmark$ & $\checkmark$ & $\checkmark$ & $\checkmark$ & $x$ & & & & & & & & 75 \\
\hline Crawley \& Sparks, 2006 & $\checkmark$ & $\checkmark$ & $\checkmark$ & $\checkmark$ & $\checkmark$ & $x$ & & & & & & & & 75 \\
\hline Doron, 2007 & $\sqrt{ }$ & $\checkmark$ & $\checkmark$ & $\checkmark$ & $\checkmark$ & $\checkmark$ & & & & & & & & 100 \\
\hline Fazel et al., 2002 & $\checkmark$ & $\checkmark$ & $\checkmark$ & $\checkmark$ & $\checkmark$ & $x$ & & & & & & & & 75 \\
\hline Fazel et al., 2004 & $\sqrt{ }$ & $\checkmark$ & & & & & $\checkmark$ & $\checkmark$ & $\checkmark$ & $\checkmark$ & & & & 100 \\
\hline Forsyth et al., 2015 & $\checkmark$ & $\checkmark$ & $\checkmark$ & $\checkmark$ & $\checkmark$ & $x$ & & & & & & & & 75 \\
\hline Handtke \& Wangmo, 2014 & $\sqrt{ }$ & $\checkmark$ & $\checkmark$ & $\checkmark$ & $\checkmark$ & $x$ & & & & & & & & 75 \\
\hline
\end{tabular}




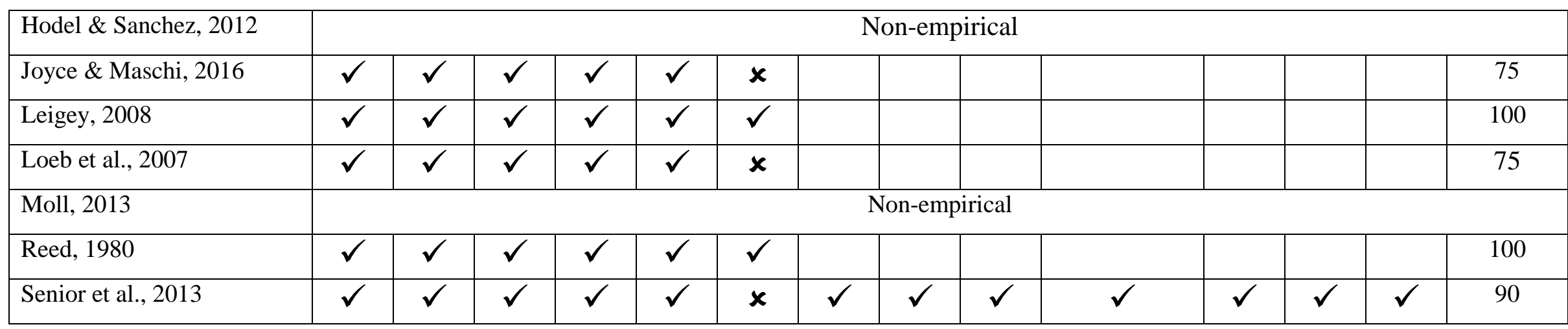

Note: Omission to report on items were rated with a negative (i.e. 'No') score on the ground that the MMAT investigates basic areas, which must be addressed in a study for it to be considered of good quality.

* Initial screening, administered to all articles, regardless of their methodology. Articles which did not pass this were discarded

** Relevant criteria from the qualitative (1) and quantitative (2) domains can be applied for mixed methods studies

*** Percentage of yes on total (excluding criteria A and B)

A. Are there clear qualitative and quantitative research questions (or objectives), or a clear mixed methods question (or objective)?

B. Do the collected data allow address the research question (objective)?

1.1. Are the sources of data (archives, documents, informants, observations) relevant to address the research question (objective)?

1.2. Is the process for analysing data relevant to address the research question (objective)?

1.3. Is appropriate consideration given to how findings relate to the context, e.g., the setting, in which the data were collected?

1.4. Is appropriate consideration given to how findings relate to researchers' influence, e.g., through their interactions with participants?

2.1. Is the sampling strategy relevant to address the research question?

2.2. Is the sample representative of the population under study?

2.3. Are measurements appropriate (clear origin, or validity known, or standard instrument)?

2.4. Is there an acceptable response rate (60\% or above)?

3.1. Is the design relevant to address the qualitative and quantitative research questions (or objectives)?

3.2. Is the integration of qualitative and quantitative data (or results*) relevant to address the research question (objective)?

3.3. Is consideration given to the limitations associated with the divergence of qualitative and quantitative data (or results*)? 
Table 3. Study characteristics

\begin{tabular}{|c|c|c|c|c|c|c|c|c|c|}
\hline Author & Year & Country & Article & Theme of article & Design & Methodology & Sample (n) & Age & Site \\
\hline Aday & 1994 & USA & Journal & Experience of imprisonment & Case-study & Qualitative & 25 & $68(\bar{x})$ & 1 \\
\hline Aday & 2005 & USA & Journal & Death & Cross-sectional & Mixed & 102 & $59(\bar{x})$ & 1 \\
\hline Aday \& Webster & 1979 & USA & Journal & Experience of imprisonment & Cross-sectional & Mixed & 40 & $55+$ & 1 \\
\hline Allen et al. & 2013 & USA & Journal & Religion & Cross-sectional & Quantitative & 94 & $45+$ & 1 \\
\hline Allen et al. & 2008 & USA & Journal & Religion & Cross-sectional & Quantitative & 81 & $50+$ & 1 \\
\hline Baidawi & 2015 & Australia & Journal & Health status & Cross-sectional & Quantitative & 233 & $50+$ & $>1$ \\
\hline Baldwin \& Leete & 2012 & Australia & Journal & Dementia & Editorial & - & - & - & - \\
\hline Barry et al. & 2015 & USA & Journal & Suicidal ideation & Cross-sectional & Quantitative & 124 & $50+$ & $>1$ \\
\hline Bishop et al. & 2014 & USA & Journal & Forgiveness & Cross-sectional & Quantitative & 261 & $45+$ & $>1$ \\
\hline Booth & 1989 & USA & Journal & Health status & Discussion paper & - & - & - & - \\
\hline Chaiklin & 1998 & USA & Journal & Treatment & Discussion paper & - & - & - & - \\
\hline Crawley & 2005 & UK & Journal & Experience of imprisonment & $\begin{array}{l}\text { Observational } \\
\text { cross-sectional }\end{array}$ & Qualitative & $80+$ & $65+$ & $>1$ \\
\hline $\begin{array}{l}\text { Crawley \& } \\
\text { Sparks }\end{array}$ & 2006 & UK & Journal & Release & $\begin{array}{l}\text { Observational } \\
\text { cross-sectional }\end{array}$ & Qualitative & $80+$ & $65+$ & $>1$ \\
\hline Doron & 2007 & Israel & Journal & Experience of imprisonment & Cross-sectional & Qualitative & 12 & $50+$ & 1 \\
\hline Fazel et al. & 2002 & $\mathrm{UK}$ & Journal & Dementia & Case-study & Qualitative & 2 & $69+$ & 1 \\
\hline Fazel et al. & 2004 & UK & Journal & Treatment & Cross-sectional & Quantitative & 203 & $60+$ & $>1$ \\
\hline Forsyth et al. & 2015 & UK & Journal & Release & Longitudinal & Qualitative & 62 & $60+$ & $>1$ \\
\hline $\begin{array}{l}\text { Handtke \& } \\
\text { Wangmo }\end{array}$ & 2014 & Switzerland & Journal & Death & Cross-sectional & Qualitative & 35 & $51+$ & $>1$ \\
\hline Hodel \& Sanchez & 2012 & USA & Journal & Dementia & Discussion paper & - & - & - & 1 \\
\hline Joyce \& Maschi & 2016 & Ireland & Report & Experience of imprisonment & Cross-sectional & Qualitative & 23 & $50+$ & $>1$ \\
\hline Leigey & 2008 & USA & Thesis & Experience of imprisonment & Cross-sectional & Qualitative & 25 & $50+$ & $>1$ \\
\hline Loeb et al. & 2007 & USA & Journal & Release & Pilot & Qualitative & 51 & $50+$ & 1 \\
\hline Moll & 2013 & UK & Report & Dementia & Report & - & - & - & $>1$ \\
\hline Reed & 1980 & USA & Thesis & Experience of imprisonment & Cross-sectional & Qualitative & 19 & $59(\bar{x})$ & 1 \\
\hline Senior et al. & 2013 & UK & Journal & Health & Cross-sectional & Mixed & 127 & $60+$ & $>1$ \\
\hline
\end{tabular}

